\title{
Knowledge of clinicians/pediatricians about neonatal resuscitation in a tertiary care hospital
}

\author{
Ayesha Muneer ${ }^{1}$, Attia Bari², \\ Arslan Haider ${ }^{3}$, Agha Shabbir Ali ${ }^{4}$
}

\begin{abstract}
Objective: To analyze the knowledge of the doctors dealing with pediatric patients about neonatal resuscitation.

Methods: This was a cross sectional study conducted at The Lahore General Hospital over one year. Total 137 doctors related to pediatrics with different job descriptions were enrolled and requested to fill a questionnaire proforma regarding their knowledge about basic equipment required and about neonatal resuscitation steps. Data was entered and analyzed using SPSS 20.

Results: Out of 137 participants, majority (71\%) had $\geq 2$ years of experience in pediatrics and $52.5 \%$ had higher postgraduate qualification. Neonatal resuscitation workshop was attended by $57 \%$ doctors. In resuscitation of newborns at the time of delivery, resuscitating doctors were assisted by nurse in $50 \%$, by junior doctor in 35\%, paramedic staff $11 \%$ and it was done by single doctor in $4 \%$ cases. Oxygen (central or $\mathrm{O}_{2}$ cylinder) and warmer facilities were available in $90 \%$ and $82 \%$ of health facilities respectively. Majority $(86 \%)$ of participants were of view that every neonate must be attended at birth. Not a single doctor followed all the standard steps of neonatal resuscitation although $90 \%$ had knowledge about resuscitation equipment and common resuscitation drugs.

Conclusion: Pediatric health care professionals had knowledge about neonatal resuscitation but there are gaps in the practical application. There is a strong need of frequent neonatal resuscitation workshops for improving neonatal outcomes.
\end{abstract}

KEYWORDS: Neonates, Resuscitation, Health Professional, Knowledge.

doi: https://doi.org/10.12669/pjms.35.3.987

How to cite this:

Muneer A, Bari A, Haider A, Ali AS. Knowledge of clinicians/pediatricians about neonatal resuscitation in a tertiary care hospital. Pak J Med Sci. 2019;35(3):775-779. doi: https://doi.org/10.12669/pjms.35.3.987

This is an Open Access article distributed under the terms of the Creative Commons Attribution License (http://creativecommons.org/licenses/by/3.0), which permits unrestricted use, distribution, and reproduction in any medium, provided the original work is properly cited.

1. Dr. Ayesha Muneer, F.C.P.S.

Assistant Professor of Pediatric Medicine

2. Dr. Attia Bari, MCPS, DCH, F.C.P.S, MHPE.

Associate Professor, Pediatric Medicine,

The Children's Hospital Lahore.

3. Dr. Arslan Haider,

(Pediatric FCPS Part II resident)

4. $\quad$ Prof. Agha Shabbir Ali, MCPS, F.C.P.S.

Pediatric Medicine,

1,3,4: The Lahore General Hospital,

Lahore, Pakistan.

Correspondence:

Dr. Attia Bari

Associate Professor, Pediatric Medicine

The Children's Hospital \& Institute of Child Health,

Lahore, Pakistan.

E-mail: drattiabari@gmail.com

* Received for Publication:

* Revision Received:

* Revision Accepted:
August 1, 2018

February 2, 2019

April 2, 2019

\section{INTRODUCTION}

The birth process is the most hazardous period of life and there are maximum number of deaths in this period as compared to deaths in all other phases of life. ${ }^{1}$ Approximately $10 \%$ of newborns require some form of resuscitation intervention immediately after birth. ${ }^{2}$ The 'Helping Babies breath' mainly focus on teaching neonatal resuscitation (NR) techniques in resource-limited settings. ${ }^{3,4}$ Providing good quality antenatal care and high quality resuscitation at birth by skilled birth attendants is a vital opportunity for all newborns to have a good start of life. ${ }^{5}$ Globally there is alarmingly high rate of death in newborn babies particularly among the world's poorest countries and average newborn mortality rate in low-income countries is 27 deaths per 1000 
births. ${ }^{6}$ A significant proportion of neonatal deaths in low and middle income countries are due to birth asphyxia and it accounts almost $25 \%$ of early neonatal deaths. ${ }^{7-9}$

NR is an essential component of maternal and child health services and is an inexpensive intervention by which many newborn lives can be saved. NR is defined as the set of interventions at the time of birth to support the establishment of breathing and circulation. The quality of NR and initial stabilization of newborn during first few minutes of birth has a significant effect on neonatal morbidity and mortality especially in high risk newborns like premature and low birth weight babies..$^{10}$ Improper NR steps/Suboptimal resuscitation is a cause of millions of neonatal deaths and almost $99 \%$ of these deaths occur in resource limiting countries. A large number of these affected newborns develop complications such as cerebral palsy and cognitive impairment. ${ }^{11}$

If the health care providers are properly trained, then the outcome of these babies can be markedly improved. When births occur in health care facilities, it is a priority to ensure that all birth attendants are competent in newborn resuscitation. It is an ironic fact that most health care providers including doctors and nurses are inadequately trained. ${ }^{12}$ In order to create change and decrease neonatal mortality the quality improvement initiative is vital through effective neonatal resuscitation. ${ }^{13}$ There is scarcity of research on this topic in our country. In this context, we planned this study to identify the knowledge gaps or appropriateness among pediatric health care providers in NR at a tertiary care hospital, Lahore, Pakistan.

\section{METHODS}

This was a descriptive observational crosssectional study conducted at Lahore General Hospital, Lahore in 2017 over a period of one year in the department of Pediatric Medicine. After taking ethical approval from Institutional Review Board, a self-administered, close-ended questionnaire about the neonatal resuscitation knowledge was distributed to pediatric health care providers including pediatricians / doctors trained and working in neonatal unit or general pediatric ward and they wereasked tocompletequestionnaire which was in two parts as; demographic information and assessment of their knowledge. The questionnaire consisted of simple questions based on basic steps done routinely during NR. Data regarding their age, qualification including postgraduate diploma or degree, experience in pediatrics, NR workshop attended and their Knowledge regarding basic steps of NR; clinical parameters of NR (following steps of resuscitation like Preparation, Safety, Shout for help and Stimulate) management (Airway, Breathing, Chest Compression, Drugs, Reassessment), equipment required for resuscitation (20 cc Syringe, bulb sucker, suction catheter, nasogastric tube, mask of different sizes, ambu bag, laryngoscope with straight blade, endotracheal tubes of different sizes), drugs required for resuscitation (epinephrine, volume expenders, sodium bicarbonate, Naloxone, Dopamine Hydrochloride), and follow up assessment and care provided were recorded. The survey was anonymous as the names of the participants were kept confidential.

Data was analyzed using SPSS (Statistical Package for Social Sciences) Version 20. Frequencies, percentages were given for qualitative variables. The results are presented using tables.

\section{RESULTS}

Out of 137 doctors' 98 (71.5\%) had > 2 years of experience in pediatrics and $(72,52.5 \%)$ had highest

Table-I: Characteristics of the study participants and health facility for resuscitation $(n=137)$

\begin{tabular}{llc}
\hline & Variables & Frequency $(\%)$ \\
\hline \multirow{4}{*}{ Qualification } & MBBS & $72(52.5)$ \\
& MCPS & $12(8.8)$ \\
& DCH & $17(12.4)$ \\
Facilities & Warmer & $36(26.2)$ \\
available/ & Oxygen & $112(82)$ \\
equipment \& & Monitor & $124(91)$ \\
monitors & Ventilator & $20(14)$ \\
& Every baby & $5(4)$ \\
How important & must be & $118(86)$ \\
is Neonatal & attended & \\
resuscitation? & Only high risk & $19(14)$ \\
& babies & $48(35)$ \\
& Doctor & $14(10.2)$ \\
Who helps you in & Paramedic & $69(50.4)$ \\
resuscitation & Nurse & $6(4.4)$ \\
Experience in & Alone & $26(19)$ \\
pediatrics & 1 year & $13(9.5)$ \\
& 2 to 2 year & $98(71.5)$ \\
& ato year & $78(57)$ \\
\hline
\end{tabular}


postgraduate qualification (FCPS) followed by diploma who delivered neonatal resuscitation. Neonatal resuscitation workshop was attended by $78(57 \%)$ doctors. In 69 (50\%) deliveries doctor provided the resuscitation with the assistance of nurse and $6(4.4 \%)$ cases the resuscitation was done alone. Majority 118 (86\%) were of the view that every neonate must be attended at birth by pediatrician. Details of neonatal resuscitation facility are shown in Table-I.

All doctors did not follow all steps of resuscitation but 117 (85\%) knew about the stimulus, drying and wrapping $110(80 \%)$. It was quite worrisome that only $64(47 \%)$ had the knowledge of how to maintain airway. Knowledge about common resuscitation drugs was $80-90 \%$ and majority $>90 \%$ knew about the necessary equipment required for resuscitation (Table-II).

\section{DISCUSSION}

To ensure the safety and health of neonates', competency in NR is critical in the delivery rooms, neonatology units and pediatric intensive care units. Each year, millions of babies do not breathe immediately at birth, and among them the majority require basic neonatal resuscitation. ${ }^{13}$ When births occur in health care facilities, it is a priority to ensure that all birth attendants are competent in resuscitation. ${ }^{5}$ The results of our present study reflect the NR practices followed in tertiary care hospital

Table-II: Steps of neonatal resuscitation followed by pediatric health care providers.

\begin{tabular}{|c|c|c|}
\hline Things to do & & Number (\%) \\
\hline \multirow{9}{*}{ Steps of resuscitation } & Preparation & $80(58)$ \\
\hline & Safety & $90(66)$ \\
\hline & Shout for help & $61(45)$ \\
\hline & How to dry and wrap & $110(80)$ \\
\hline & Gentle tactile stimulation & $117(85)$ \\
\hline & How to maintain airway & $64(47)$ \\
\hline & Breathing & $95(69)$ \\
\hline & Chest Compression & $98(72)$ \\
\hline & Re-assessment & $91(66)$ \\
\hline \multirow{2}{*}{$\begin{array}{l}\text { How frequently you check equipment required } \\
\text { for resuscitation? }\end{array}$} & Every time & $96(70)$ \\
\hline & Occasionally & $41(30)$ \\
\hline \multirow{2}{*}{$\begin{array}{l}\text { How frequently do you check drugs required for } \\
\text { resuscitation? }\end{array}$} & Regularly & $114(83)$ \\
\hline & By Chance & $23(17)$ \\
\hline \multirow{8}{*}{ Availability of priority items or equipment type } & 20 cc Syringe & $115(84)$ \\
\hline & Bulb sucker & $125(91)$ \\
\hline & Suction catheter & $102(75)$ \\
\hline & NG tube & $128(93)$ \\
\hline & Mask of different sizes & $103(75)$ \\
\hline & Ambu bag with pressure valve & $127(93)$ \\
\hline & Laryngoscope with straight blade & $125(91)$ \\
\hline & Endotracheal tubes of different sizes & $126(92)$ \\
\hline \multirow{3}{*}{$\begin{array}{l}\text { How frequently do you check drugs required for } \\
\text { resuscitation? }\end{array}$} & Every time & $110(80)$ \\
\hline & Occasionally & $27(20)$ \\
\hline & Epinephrine & $126(92)$ \\
\hline \multirow{4}{*}{ Awareness about availability of Essential Drugs } & Volume Expenders & $114(83)$ \\
\hline & Sodium bicarbonate & $120(88)$ \\
\hline & Naloxone Hydrochloride & $106(77)$ \\
\hline & Dopamine Hydrochloride & $113(83)$ \\
\hline
\end{tabular}


where proper obstetric facilities for deliveries and neonatal unit including neonatal intensive care are available.

Despite the fact that our all participants belonged to pediatrics and questions were designed to assess simple base line knowledge, our participants were not able to mention all the steps of resuscitation accurately. Although majority $71.5 \%$ had $>2$ years of experience in pediatrics and had an experience of NR, only $45 \%$ were aware of the importance of shout for help and $72 \%$ accurately knew about the proper chest compression site and ventilation compression ratio. A similar study from India showed that only $35.4 \%$ of the participants managed to score above the minimum competency level of $>85 \%$. In their study, participants had $>9$ years of work experience. ${ }^{14}$ Our results are much better than this study as $52.5 \%$ of our participants had postgraduate qualification of FCPS. Both our and this study showed deficiency in knowledge of basic NR and many health personnel have limited knowledge of NR. These findings reflect the status of medical institutions in Pakistan that there are no regular refresher courses, or it is suboptimal training on essentials of NR.

Nurses are an integral part of team in delivery room and they must be well trained to provide initial resuscitation to newborns. In a study from India also a similar performance was reported where only $34 \%$ scored above $85 \%$ in NR steps. ${ }^{15}$ Training in NR for nurses, pediatric residents, and residents of obstetrics and gynecology must be emphasized as supported by a study done in Ethiopia showing substandard NR knowledge and skills. ${ }^{16}$ In our study, $57 \%$ had training in NR workshop which is comparable with a study from India which also showed that $57 \%$ received training in newborn care. In their study $48 \%$ had knowledge of positive pressure ventilation, $13 \%$ could provide chest compression or drugs during resuscitation. ${ }^{17}$ The important finding in this study was that most of the health workers did not had knowledge about NR. Our study showed much better results than this study findings as $>60$ percent showed appropriate knowledge of initial steps of resuscitation except of shouting for help and how to maintain airway. This difference is probably due to the difference that our hospital is a tertiary care hospital and majority had some form of postgraduate qualification. So, these findings showed that the knowledge about the NR could be changed by attending the refresher courses or workshops on NR. ${ }^{18}$ This is also supported by a study done by Bansal et al. from India in which the participant who underwent NR training were following correct practices as compared to those without the training. ${ }^{19}$

The primary steps in NR are very crucial in neonatal outcome and these include only the practices of suction to take a breath, drying, stimulating, keeping them warm, airway examination and assessment of breathing. These essential steps generally occur within the first few seconds of baby's birth making rapid assessment of correct practice to save a life. A study from Pakistan published recently was conducted in obstetric department has shown similar results like ours, $58 \%$ of participants in this study showed correct initial steps for NR in labor room. ${ }^{8}$

The newborn babies who required extensive resuscitation should have ongoing post resuscitation assessment for next 24-48 hours after birth. Even those babies who respond well to initial simple resuscitation support may sometimes need further intervention in next few hours. ${ }^{20}$ In our study, only $66 \%$ had the perception of importance of reassessment of the baby after initial NR. Sometimes the gains from successful NR can be lost due to poor follow-up and aftercare and not attending to potential complications which may occur in next $24-48$ hours.

Limitations: The present study had several limitations. Only sampling pediatric doctors might mean that these results are not applicable to other health care professionals like nurses and obstetric doctors who are always at the forefront when a baby is delivered. Secondly the study participants were from only one tertiary care center of Lahore limiting the generalization of our results to others. More studies are required from other institutes as well and further studies to explore the reasons for the lack of understanding of NR to examine the all health care professional participating in newborn delivery.

\section{CONCLUSION}

Pediatric health care professionals had knowledge about neonatal resuscitation but there are gaps in the knowledge which must be addressed. There is need to reassess the knowledge and skills of doctors and nurses providing NR and follow up by periodic NR refresher workshops and evaluation. Teaching on NR should be stressed during undergraduate and postgraduate medical education to ensure better neonatal outcome. 


\section{Conflict of interest: None.}

\section{Grant Support \& Financial Disclosures: Nothing to} declare.

\section{REFERENCES}

1. Ezenduka PO, Ndie EC, Oburoh ET. Assessment of knowledge, attitude, and practice of nursing management of birth asphyxia in federal medical centre Asaba, Delta StateNigeria. Cinical Nurs Stud. 2016;4(2):21-27. doi:0.5430/cns. v4n2p21.

2. Vali P MBLS. Neonatal resuscitation: evolving strategies. Matern Heal Neonatol Perinatol. 2015;1-14. doi:10.1186/ s40748-014-0003-0

3. Bang A, Patel A, Bellad R, Gisore P, Goudar SS, Esamai $\mathrm{F}$, et al. Helping Babies Breathe $(\mathrm{HBB})$ training: What happens to knowledge and skills over time? BMC Pregnancy and Childbirth. 2016;16(364):1-12. doi:10.1186/s12884-016-1141-3

4. Kamath-rayne BD, Berkelhamer SK, Kc A, Ersdal HL, Niermeyer S. Neonatal resuscitation in global health settings: an examination of the past to prepare for the future. Pediatric RESEARCH; 2017;82(2):194-200. doi. org/10.1038/pr.2017.48

5. Vesel L, Bergh AM, Kerber KJ, Valsangkar B, Mazia G, Moxon SG, et al. Kangaroo mother care: A multi-country analysis of health system bottlenecks and potential solutions. BMC Pregnancy Child Birth. 2015;15(2):1-20. doi:10.1186/1471-2393-15-S2-S5.

6. Unicef for every child. World is failing newborn babies, says UNICEF; press release.

7. Medicus AI. Newborn Resuscitation Training in Resource-Limited Settings: A Systematic Literature Review. Pediatrics. 2016;138(2):1-16. doi:10.1542/ peds.2015-4490.

8. Ayaz A, Saleem S. Neonatal Mortality and Prevalence of Practices for Newborn Care in a Squatter Settlement of Karachi, Pakistan: A Cross-Sectional Study. PLoS ONE. 2010;5(11):1-6. doi:10.1371/journal.pone.0013783.

9. Vidyasagar D. A global view of advancing neonatal health and survival. J Perinatol. 2002;22:513-515. doi:10.1038/sj.jp.7210797.

10. Braga MS, Kabbur P, Alur P, Goodstein MH, Roberts KD, Satrom K, et al. Current practice of neonatal resuscitation documentation in North America: A multicenter retrospective chart review. BMC Pediatr. 2015;15(1):1-7. doi:10.1186/s12887-015-0503-8.

11. Noor T, Raza N,Haq G. Neonatal resuscitation: A knowledge gap amongst obstetrical trainees A Cross-sectional survey amongst medical graduates of Civil Hospital Karachi. J Pak Med Assoc. 2014;64(7):856-859.
12. Couper ID, Thurley JD, Hugo JFM. The neonatal resuscitation training project in rural South Africa. Rural Remote Health. 2005;5(4):1-10.

13. Heerden C Van, Maree C, Africa S, Africa S, Maree C. Strategies to sustain a quality improvement initiative in neonatal resuscitation. African J Prim Heal Care Fam Med. 2016;1-10. doi:10.4102/phcfm.v8i2958.

14. Florence Murila, Moses Madadi RM. Assessment of Knowledge on Neonatal Resuscitation amongst Health Care Providers. Pan Afr Med J. 2012;11(78):1-5.

15. Suresh PM, Kumar TR, Nagalekshmi R, Anandan $H$. Evaluation of Knowledge and Practices on Neonatal Resuscitation among Nurses in Kanyakumari District Hospitals. Int J Sci Study. 2017;5(10):166-168. doi: 0.17354/ ijss/2017/181.

16. Gebreegziabher E, Aregawi A, Getinet H. Knowledge and skills of neonatal resuscitation of health professionals at a university teaching hospital of Northwest Ethiopia. World J Emerg Med. 2014;5(3):196-202. doi:10.5847/ wjem.j.1920-8642.2014.03.007

17. Louis D, Kumar P, Gupta A. Knowledge and practices of healthcare providers about essential newborn care and resuscitation in a district of Haryana. J Ind Med Assoc. 2013;11(2):114-117.

18. Trevisanuto D, Bertuola F, Lanzoni P, Cavallin F, Matediana $\mathrm{E}$, Manzungu $\mathrm{OW}$ et. al. Effect of a neonatal resuscitation course on healthcare providers' performances assessed by video recording in a low-resource setting. PLoS One. 2015;1-12. doi:10.1371/journal.pone.0144443

19. Bansal SC, Nimbalkar AS, Patel DV, Sethi AR, Phatak AG, Nimbalkar SM. Current Neonatal Resuscitation Practices among Paediatricians in Gujarat. India. Int J Pediatr. 2014;2:1-7. doi:10.1155/2014/676374

20. Akinloye AO, Connell CO. Post-Resuscitation Care for Neonates Receiving Positive Pressure Ventilation at Birth. Pediatrics. 2014;134(4):1057-62.doi: 10.1542/ peds.2014-0554

\section{Author's Contribution:}

AM: Conceived idea, data collection.

AB: Main author, manuscript writing.

AH: Data management.

ASA: Critical review, final approval. 